\title{
Diagnostic Utility of Color Doppler Ultrasound for Nuchal Cord Detection at Term: A Prospective Study
}

\author{
GAMAL A. IBRAHIM, M.D.; MOSTAFA A. SAFWAT, M.Sc. and SHERINE H.M. GADALLA, M.D. \\ The Department of Obstetrics \& Gynecology, Faculty of Medicine, Cairo University
}

\begin{abstract}
Background: Nuchal cords are very common, with prevalence rates ranging from $18 \%$ to $25 \%$. Color Doppler sonography is a noninvasive method that can be used for nuchal cord diagnosis.
\end{abstract}

Aim of Study: In this study, we investigated the diagnostic accuracy of color Doppler ultrasound (US) in the detection of nuchal cord among full term pregnant women.

Material and Methods: We conducted a prospective study on 250 full term pregnant women, who were examined by two-dimensional US and color Doppler US to detect nuchal cord presence. Only women with cephalic presentation and sonographicaly detected nuchal cord were included.

Results: The mean age of studied group was $26.86 \pm 5.53$ years and the mean parity was $1.59 \pm 1.21$. The mean gestational age was $38.24 \pm 1.218$ weeks and the estimated fetal weight was $3.236 \pm 0.378 \mathrm{Kg}$. Overall, the twodimensional US detected $64 \%$ of the nuchal cord loops; while the color Doppler US detected 100\% of the loops. Besides, the frequency of loops of cord around the neck detected after delivery was $94 \%$; which was one loop in $83 \%$ of the cases. Accuracy of 2D US in detecting cord around the neck was $61.2 \%$, while that of color Doppler is $94 \%$.

Conclusions: In conclusion, the accuracy of detecting the nuchal cord is more with color Doppler US than twodimensional US.

Key Words: Nuchal cord-2D US-Color Doppler-Cord around fetal neck.

\section{Introduction}

THE interest in the presence and clinical implications of nuchal cord has increased over the years owing to is potential hazards on fetal and mother health. The condition is described as 360 degrees rotation of the umbilical cord around the neck of

Correspondence to: Dr. Gamal A. Ibrahim, The Department of Obstetrics \& Gynecology, Faculty of Medicine, Cairo University the fetus [1]. The current figures demonstrate substantial variations in the incidence of nuchal cord at term delivery, ranging from $10-30 \%$ [2,3]. While the exact mechanisms underlying the development of nuchal cord are not clear yet, it is widely thoughts that alterations in the biomechanics of umbilical cords (such as imbalance between blood flow and fetal movement, imbalance in the growth of the right and left vessels, improper tensile strength and elastic forces) coupled with abnormalities in the placental/amniotic fluid volumes contribute significantly in the development of nuchal cord $[4,5]$.

There are many forms of nuchal cords, which range between the loose or tightly wrapped, single or multiple loops around the neck [6]. Nuchal cords can cause problems when a cord is tightly wrapped around the neck, leading to fetal strangulation and umbilical cord compression [1]. Anemia, hypovolemia, and acidosis can be attributed to the obstruction of blood flow resulting from the umbilical cord compression [7,8]. In some cases, infants might have physical features (e.g., asphyxia) secondary to tight nuchal cords [9].

Ultrasonography can be used to diagnose nuchal cords antenatally. Color Doppler sonography is a noninvasive method that can be also used for nuchal cord diagnosis. The gray-scale visualization of the " divot' sign makes a sonographic diagnosis of the cord possible. Doppler Flow Velocimetry is capable for detecting fetal impaired resistance or increased downstream resistance before the occurrence of irreversible adverse effects. Up to now, most nuchal cord perinatal studies have focused on fetal hypoxia occurring during delivery. A general literature review revealed few published studies on the implications of uterus's nuchal cord. In this study, 
we investigated the diagnostic accuracy of color Doppler ultrasound (US) in the detection of nuchal cord among full term pregnant women.

\section{Patients and Methods}

This cross sectional study was conducted on 250 pregnant women (out of 1250 pregnant women scanned to detect nuchal cord) admitted to Kasr Al Ainy Maternity Hospital in the period from August 2014 to December 2017. The study was conducted only after obtaining approval of Ethical Committee Faculty of Medicine, Cairo University and written informed consent from all the participants.

\section{Study participant:}

The present study included consecutive adult women with full-term, singleton, pregnancy (3740 weeks of gestation). Only women with cephalic presentation and sonographicaly detected nuchal cord were included. Women with pregnancy-related disorders (such as hypertension and gestational diabetes), congenital anomalies, multiple pregnancy, oligohydramnios, polyhydramnios, and/or history of previous cesarean section or scarred uterus were excluded.

All eligible women underwent full history taking and clinical examination. Besides, the following routine laboratory parameters were obtained. The presence of nuchal cord was confirmed at time of delivery and number of loops around the neck were recorded.

\section{Ultrasound examination:}

Eligible women underwent two-dimension and color Doppler ultrasonography using an S SD- 1700 ultrasound scanner (Aloka, Tokyo, Japan) equipped with a $3.5-\mathrm{MHz}$ convex-array transducer. The screening was carried out in the transverse and sagittal planes of the neck, which was diagnosed when the cord was visualized lying along at least three of the four sides of the neck. The existence of the nuchal cord was graded as present, nonpresent as well as the number of loops.

\section{Statistical analysis:}

Data were analyzed using Statistical Program for Social Science (SPSS) version 20.0. We employed descriptive analysis [mean \pm standard deviation (SD) and frequency for quantitative and qualitative data, respectively] to describe different parameters of the study. The independent $t$-test or Mann-Whitney test were used to assess the association between erectile index and different parameters.

\section{Results}

The mean age of studied group was $26.86 \pm 5.53$ years and the mean parity was $1.59 \pm 1.21$. The mean gestational age was $38.24 \pm 1.218$ weeks and the estimated fetal weight was $3.236 \pm 0$. $378 \mathrm{Kg}($ Table 1$)$.

Overall, the two-dimensional US detected 64\% of the nuchal cord loops; while the color Doppler US detected $100 \%$ of the loops. Besides, the frequency of loops of cord around the neck detected after delivery was $94 \%$; which was one loop in $83 \%$ of the cases (Fig. 1).

The sensitivity of two-dimensional US in detecting cord around the neck is $63 \%$ while that of color Doppler was $100 \%$. In addition, the specificity of 2D US in detecting cord around the neck was $26.6 \%$, while that of color Doppler could not be assessed as all women included in this study was diagnosed as nuchal cord by color Doppler (one of the study inclusion criteria) so there is no true negative or false negative data. Accuracy of 2D US in detecting cord around the neck was $61.2 \%$, while that of color Doppler is $94 \%$ (Table 2).

Table (1): Baseline characteristics of the included women.

\begin{tabular}{lllllc}
\hline & $\mathrm{N}$ & Minimum & Maximum & Mean & SD \\
\hline Age & 250 & 17 & 39 & 26.86 & \pm 5.536 \\
Parity & 2500 & 5 & 1.59 & \pm 1.207 \\
GA & 25037 weeks & 40 weeks & 38.24 weeks \pm 1.218 \\
EFW & $2502.4 \mathrm{~kg}$ & $4.2 \mathrm{~kg}$ & $3.236 \mathrm{~kg}$ & \pm 0.3789 \\
\hline
\end{tabular}

Table (2): Sensitivity, specificity and accuracy of 2D US Vs color Doppler in detecting loops of cord around the neck.

\begin{tabular}{lll}
\hline & 2D US & Color Doppler \\
\hline True positive & 149 & 235 \\
False negative & 86 & 0 \\
True negative & 4 & 0 \\
False positive & 11 & 15 \\
Sensitivity & $63.4 \%$ & $100 \%$ \\
Specificity & $26.67 \%$ & \\
(+)ve predictive value & $93.13 \%$ & $94 \%$ \\
(-)ve predictive value & $4.44 \%$ & - \\
Accuracy & $61.20 \%$ & $94 \%$ \\
\hline
\end{tabular}




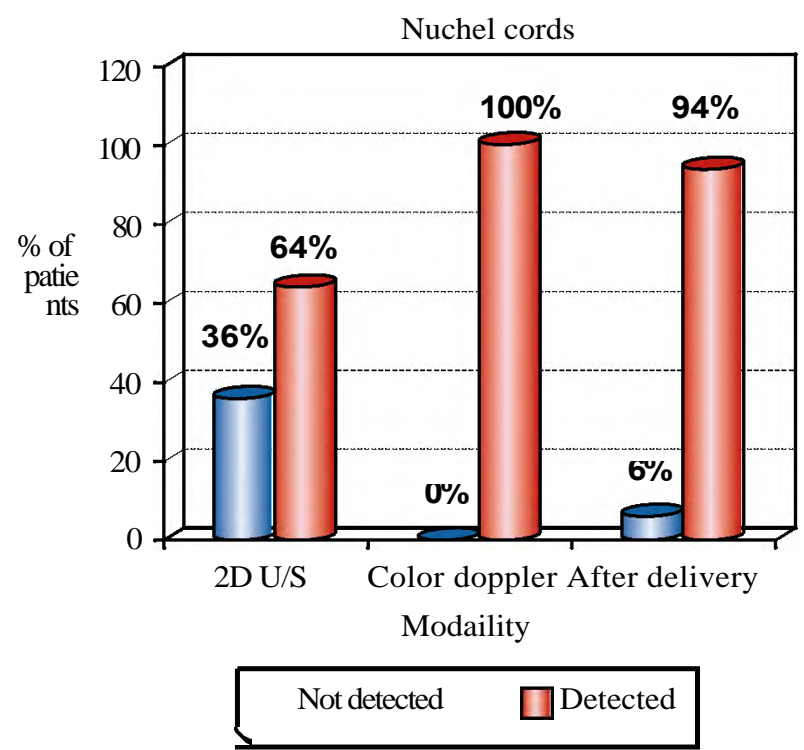

Fig. (1): Frequency of detected loops by 2D, Color Doppler US, and after Delivery.

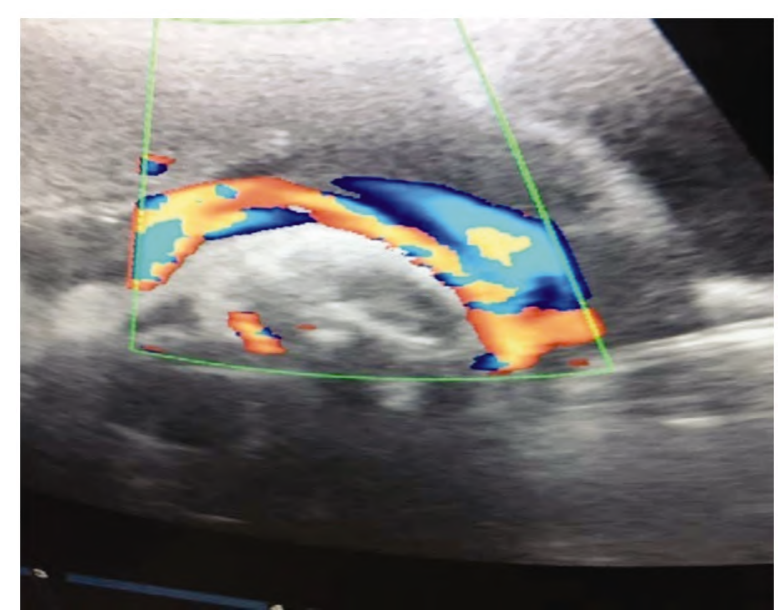

Fig. (2): Color Doppler image of umbilical cord around fetal neck.

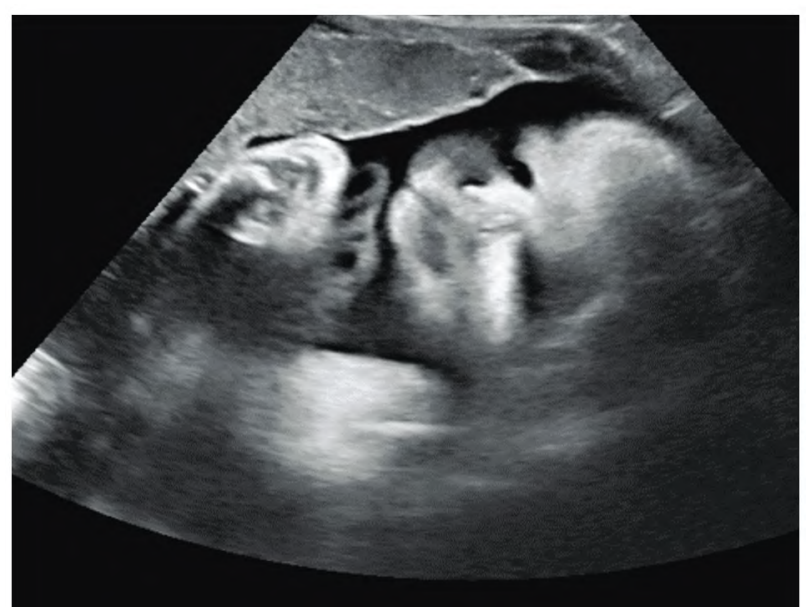

Fig. (3): 2D US picture of umbilical cord at right side of fetal head.

\section{Discussion}

During labor, cord accidents are frequent, especially nuchal cord, which can be associated with repeated and variable shortening or absent in the end-diastolic flow [1]. It was recorded that approximately $20 \%$ of deliveries had a nuchal risk [10]. Antenatal ultrasound diagnosis needs good monitoring before and during pregnancy, depending on not only the type of machine but the operator's skill as well.

In the present study, our findings showed that the 2D US is useful in the nuchal cord diagnosis with a sensitivity, specificity, and accuracy of $63.4 \%, 26.67 \%$, and $61.2 \%$, respectively. On the other hand, color Doppler is a useful diagnostic tool with an overall accuracy of $94 \%$. Obviously, the color Doppler ultrasound has a higher sensitivity and accuracy than two-dimensional ultrasound in the prediction of the nuchal cord occurrence prior to delivery.

Hanaoka $U$ et al., [11] demonstrated that there were no substantial differences between Color Doppler ultrasound and two-dimensional ultrasound in terms of the nuchal cord detection. On the other hand, a study was done by Qin Y et al. [12], showed that the Color Doppler sensitivity was $96.8 \%$, with a significantly better $(p<0.05)$ accuracy in identifying nuchal cord during delivery compared to grey-scale imaging alone. This agrees with our findings, where the overall accuracy of color Doppler was $94 \%$ while that of the 2 D US $61.2 \%$.

The incidence of the nuchal cord was $18.8 \%$, and the single loop was the most common finding in our study that is nearly close to the reported incidence of Singh et al. [13], $(18.57 \%)$ and Joshi et al. [14], (19.76\%). Of the 235 neonates with nuchal cords in the study group, $208(88.5 \%)$ had one loop, $21(8.9 \%)$ had two loops, and only 6 ( $2.6 \%$ ) had three loops. Likewise, Shrestha et al. [ 15], reported that single nuchal cord loops were most common than multiple nuchal cord loops. In our study, the nuchal cord incidence was more in multigravida ( $80 \%$ ) in comparison to primigravida ( 20\%). Similarly, Onderoglu et al. [16], quoted that the incidence of nuchal cord loop in the case of multigravida was higher $(65.1 \%)$ compared to primigravida (34.9\%). On the other hand, Tamrakar et al. [17], mentioned that a prevalent incidence of nuchal cord loop in the case of primigravida ( $62.98 \%$ ), but no obvious reason was stated for this.

One of limitation of our study is that Doppler imnedance of umhilical arterv was not measured 
in patients suspected having nuchal cord antipartumly that might help in detecting patients with suspected complications to offer early management to avoid adverse perinatal effect and NICU admissions. Large sample may be needed to set cutoff value of Doppler ominous signs for early interference in those patients

\section{Conclusion:}

In conclusion, the accuracy of detecting the nuchal cord is more with color Doppler ultrasound than two-dimensional ultrasound. The use of color Doppler flow has increased the accuracy of this prenatal diagnosis. Although accuracy of color Doppler is better than that of two-dimensional US, two-dimensional US can be used as a screening tool in women attempting vaginal delivery and if nuchal cord is suspected, it should be confirmed by an experienced sonographer or by the use of color Doppler ultrasound to confirm the diagnosis.

\section{References}

1- PEESAY M.: Nuchal cord and its implications. Matern Heal Neonatol. Perinatol., 3 (1): 28, 2017.

2- HENRY E., ANDRES R.L. and CHRISTENSEN R.D.: Neonatal outcomes following a tight nuchal cord. J. Perinatol., 33 (3): 231-234, 2013.

3- LARSON J.D., RAYBURN W.F., CROSBY S. and THURNAU G.R.: Multiple nuchal cord entanglements and intrapartum complications. Am. J. Obstet. Gynecol., doi: 10. 1016/0002-9378(95)91359-9, 1995.

4- LACRO R.V., JONES K.L. and BENIRSCHKE K.: The umbilical cord twist: Origin direction, and relevance. Am. J. Obstet. Gynecol., doi: 10.1016/S0002-9378(87) 80067- 4, 1987.

5- HORN L.C., FABER R., STEPAN H, SIMON E., ROBEL R. and WITTEKIND C.: Umbilical cord hypercoiling and thinning: A rare cause of intrauterine death in the second trimester of pregnancy. Pediatr. Dev. Pathol., doi: 10.2350/08-05-0095.1, 2006.
6- GIACOMELLO F.: Ultrasound determination of nuchal cord in breech presentation. American Journal of Obstetrics and Gynecology, doi: 10.1016/S0002-9378(88)80123-6, 1988.

7- BAERGEN R.N.: Cord abnormalities, structural lesions, and cord 'accidents'. Semin Diagn. Pathol., doi: 10.1053/ j. semdp.2007.02.004, 2007.

8- SHEPHERD A.J., RICHARDSON C.J. and BROWN J.P.: Nuchal Cord as a Cause of Neonatal Anemia. Am. J. Dis. Child., 139 (1): 71-73, 1985.

9- PEESAY M.: Cord around the neck syndrome. BMC Pregnancy and Childbirth, doi: 10.1186/1471-2393-12S1-A6, 2012.

10- TAHMASEBPOUR A., RAFIEE N.B., GHAFFARI S. and JAMAL A.: Increased nuchal translucency and pregnancy outcome. Iran J. Public Health, 41 (11): 92-7, 2012.

11- HANAOKA U., YANAGIHARA T., TANAKA H. and HATA T.: Comparison of three-dimensional, twodimensional and color Doppler ultrasound in predicting the presence of a nuchal cord at birth. Ultrasound Obstet. Gynecol., 19 (5): 471-474, 2002.

12- QIN Y., WANG C.C., LAU T.K. and ROGERS M.S.: Color ultrasonography: A useful technique in the identification of nuchal cord during labor, 2000.

13- SINGH G. and SIDHU K.: Nuchal Cord: A retrospective analysis. Med J Armed Forces India, doi: 10.1016/S03771237(08)80102-5, 2008.

14- JOSHI K., SAXENA R., BHAT M., LOMROD Y. and VERMA K.: Incidence of cord around the neck and its effects on labour and neonatal outcome. Adv. Hum. Biol., doi: 10.4103/2321-8568.199535, 2017.

15- SHRESTHA N.S. and SINGH N.: Nuchal cord and perinatal outcome. Kathmandu Univ. Med. J., doi: 10.1097/ 00006250-200304001-00171, 2007.

16- ÖNDEROGLU L.S., DURSUN P. and DURUKAN T.: Perinatal features and umbilical cord blood gases in newborns complicated with nuchal cord. Turk J. Pediatr., 2008.

17- TAMRAKAR S.R.: Incidence of nuchal cord, mode of delivery and perinatal outcome: A notable experience in Dhulikhel Hospital - Kathmandu University Hospital. Nepal Med. Coll. J., 2013. 


\section{استخدام الدوبلر الملون لتشخيص الحبل الحبل السرى القفوى

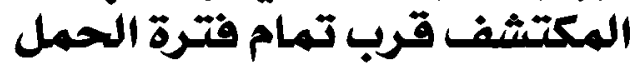

يعرف الحبل السرى حله رقبة الجنين على أنه الحبل السرى الذى يحيط بالرقبة من كل الجوانب ليكمل لفة كاملة واحدة على الأقل. وقد

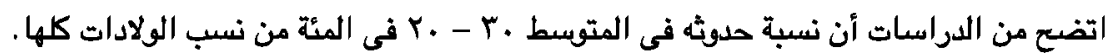

ويعد إكتثاف وجود الحبل السرى حهل رقبة الجنين هو تثخيص رجعى ما بعد الولادة. وقد تعددت طرق إكتشاف الحبل السرىى حهل

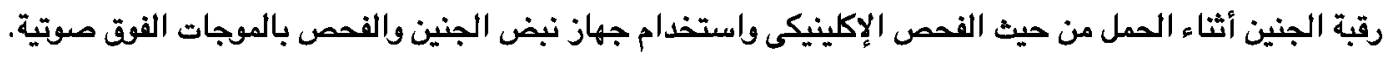

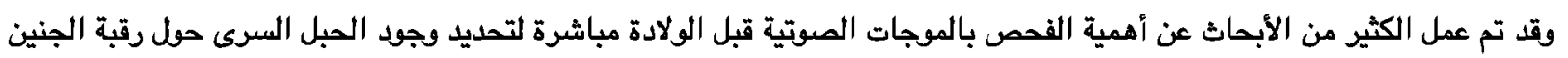

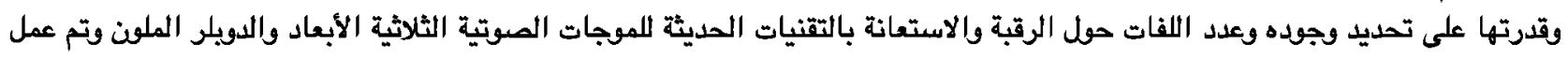

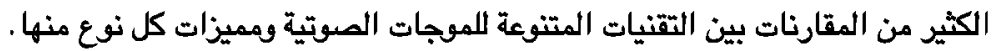

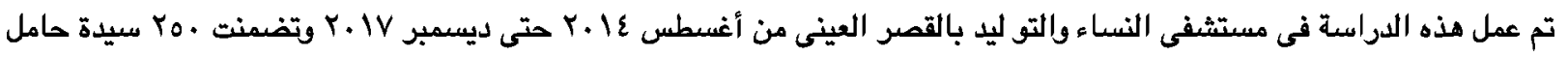

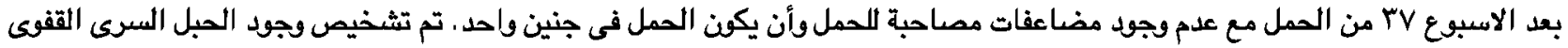
فى • بم حالة عن طريق الموجات الصوتية ثنائية الأبعاد والدوبلر الملون.

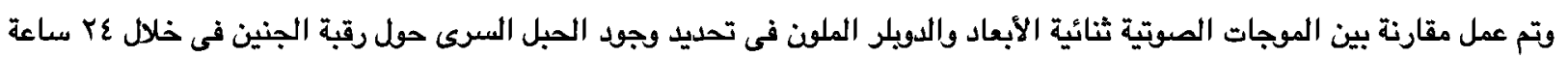

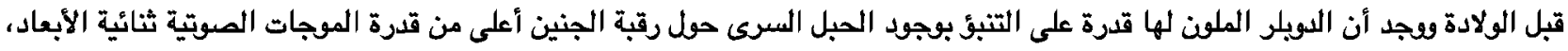

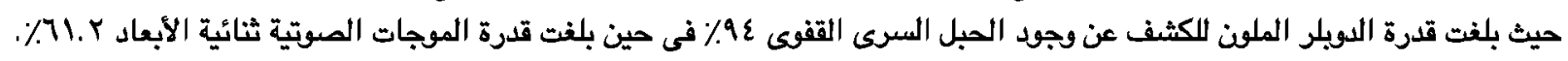

